\title{
Impact of the COVID-19 Pandemic on Treatment and Oncologic Outcomes for Cancer Patients in Romania
}

\author{
OANA GABRIELA TRIFANESCU ${ }^{1,2}$, LAURENTIA GALES ${ }^{1,2}$, XENIA BACINSCHI $^{2,3}$, LUIZA SERBANESCU ${ }^{1,2}$, \\ MIHAI GEORGESCU ${ }^{2,3}$, ALEXANDRA SANDU ${ }^{2,3}$, ALEXANDRU MICHIRE $^{2,3}$ and RODICA ANGHEL AN $^{2,3}$ \\ Departments of ${ }^{1}$ Oncology and ${ }^{3}$ Radiation Therapy, \\ "Prof. Dr. Alexandru Trestioreanu” Oncology Institute, Bucharest, Romania; \\ ${ }^{2}$ Department of Oncology, "Carol Davila” University of Medicine and Pharmacy, Bucharest, Romania
}

\begin{abstract}
Background/Aim: This study aimed to assess the impact of the ongoing COVID-19 pandemic on cancer patients, known to be immune-compromised due to the disease itself, oncological treatments and adjuvant medicines use such as steroids. Overall survival was determined for patients with COVID-19 infection and stratification according to known comorbidities and complications was performed. Patients and Methods: This prospective study included ninety cancer patients with COVID-19 confirmed by PCR testing performed before each cycle of chemotherapy or every two weeks during radiotherapy between May and December 2020 in two tertiary Cancer Centers. Demographic, cancer-related and SARSCoV-2 infection data were collected and long-term oncologic outcome was assessed. Results: Mean age of cancer patients diagnosed with SARS-CoV-2 was 59.7 \pm 12.1 years (range $=30$ 83 years). Fifty-two (57.7\%) were women. The most frequent cancer localization was breast $(n=28,31.1 \%)$ followed by colorectal $(n=11,12.2 \%)$ and lung cancer $(n=8,8.8 \%)$. Most patients infected with SARS-CoV-2 were diagnosed in stage IV of the disease $(n=44,48.9 \%)$ followed by stage III $(n=19$, $21.1 \%$ ) and stage II disease (18.9\%). Regarding comorbidities, the most common was hypertension $(n=31)$ followed by cardiac dysfunction $(n=23)$ and type II diabetes $(n=13)$. Of 27 (30\%) patients who needed hospitalization, 4 patients developed severe infection, 17 patients had mild symptoms and 6 patients were minimally symptomatic. After a median follow-up of 22.5 months, 5 patients (5.55\%) died due to SARS-COV-2 infection, all stages III and IV. Median estimated overall survival was 14 months in patients who died
\end{abstract}

This article is freely accessible online.

Correspondence to: Luiza Serbanescu, Oncology Department, "Prof. Dr. Alexandru Trestioreanu" Oncology Institute, Sos. Fundeni nr 252, Bucharest, Romania. E-mail: luizaserbanescu@yahoo.com

Key Words: COVID-19, cancer patients, chemotherapy, radiotherapy. because of COVID infection compared to 98 months in cancer-related mortality analysis $(p<0.0001)$. Three deaths occurred during chemotherapy, 1 death in the chemoradiotherapy radiotherapy group. Conclusion: SARS-CoV-2 infection was associated with an excess mortality in our study population, especially in patients with advanced and metastatic disease and in those receiving immunosuppressive treatment such as chemotherapy and radiotherapy.

Severe acute respiratory syndrome coronavirus 2 (SARSCoV-2) and the resulting illness, COVID-19, have emerged as a global pandemic (1). In 2003, the SARS epidemic was correlated with a coronavirus. The new coronavirus (2019nCoV), first appeared in December 2019 in Wuhan (China) as the perpetuator of severe respiratory infection in humans (2). The World Health Organization (WHO) made the assessment that COVID-19 must be defined and treated as a pandemic in March 2020. The human coronavirus disease COVID-19 became the fifth registered pandemic sequent to the 1918 Spanish flu, 1957 Asian flu, 1968 Hong Kong flu and the 2009 Pandemic flu (3). In September 2021, the total number of confirmed cases of SARS-CoV-2 infection was $229,222,879$ worldwide. The total number of deaths allocated to this disease was $4,702,936$. Some countries did not compile this data and many recoveries from both confirmed and untested infections remain unregistered. Unfortunately, this is still an ongoing pandemic (4).

Certain patients have a higher risk for severe illness from COVID-19 than others (5). In America, the Centers for Disease Control and Prevention single out that individuals who are 65 years and older who have underlying medical conditions, especially if they are not well controlled or if they live in a long-term care facility, are at a high risk of severe disease due to COVID-19 infection. Likewise, in Europe, the Centre for Disease Prevention and Control, identified as risk factors for a more critical disease, some underlying pathology and the age category $>70$ years old. The United Kingdom National Health Service enclosed in 
the highest clinical COVID-19 risk group: those at high risk for infections (due to immunosuppressive therapies), patients with specific cancers or severe respiratory diseases, solid organ transplant recipients, pregnant women with significant heart disease (6).

Cancer patients, especially those who undergo systemic anticancer treatments, have been thought to be at increased risk of mortality from COVID-19 and experiences from other countries show that patients with serious health conditions associate with a higher mortality risk $(7,8)$. Patients with cancer might be immunocompromised by the effects of antineoplastic therapy, adjuvant medications such as steroids, and the immunosuppressive effect of cancer itself. Mortality from COVID-19 in cancer patients is mainly determined by age, gender, and comorbidities (9).

Dealing with shortages and lockdowns, the immediate reaction of the oncology community was ruled by the general principle of risk-to-benefit ratios. Our community suddenly had to protect a population that was already vulnerable to a potentially fatal infection, without jeopardizing cancer treatments (10).

The aim of this study was to assess the impact of the pandemic in patients with different solid tumors.

\section{Patients and Methods}

Study design. A prospective study was conducted on cancer patients diagnosed with SARS-COV2 who were undergoing treatment at the medical oncology and radiotherapy department in two tertiary cancer centers, between May and December 2020. All patients were routinely tested for SARS-CoV-2 before each cycle of systemic treatment, every two weeks during radiotherapy or before the first follow-up visits. In order to identify coronavirus patients, nasopharyngeal and oropharyngeal swab samples were collected for RT-PCR testing. Currently, the gold standard test for SARS-CoV-2-specific ribonucleic acid (RNA) is based on the reverse transcription quantitative polymerase chain reaction (RTqPCR), which relies on target amplification by Taq polymerase and uses a fluorescent resonance energy transfer (FRET)-based hydrolysis probe (11)

Patient characteristics. A total of ninety patients were included in the study. Demographic data (age, gender), cancer related data (type of cancer, stage, comorbidities, treatment objective, type of treatment, oncologic treatment adverse events) and SARS CoV2 infection information (symptoms, disease severity, treatment, blood count parameters, symptomatic treatment, infection complications) were collected prospectively. Toxicity of blood count parameters were quantified using CTCAE v.4.0 (12). Oncologic outcome was measured by overall survival assessment (define as time from cancer diagnosis to death of any cause). SARS-COV 2 outcome was defined as resulted when a RT-PCR test was negative and SARS$\mathrm{CoV}-2$ impact on mortality was assessed using Kaplan Meyer and Cox regression analysis.

Informed consent was obtained from the patients and ethics committee approval was obtained before the commencement of this study. Patient characteristics are presented in Table I.
Table I. Patient characteristics.

\begin{tabular}{lcc}
\hline Parameter & Feature & Count/Mean (\%/range) \\
\hline Age & & $59.7(30-83)$ \\
Gender & Female & $52(58)$ \\
& Male & $38(42)$ \\
Cancer & Breast & $27(30)$ \\
localization & Gastrointestinal & $15(16.6)$ \\
& Skin & $10(11.1)$ \\
& Gynecologic & $9(10)$ \\
& Urinary & $10(11.1)$ \\
& Lung & $8(8.9)$ \\
& Central nervous system & $5(5.6)$ \\
Stage & Head and neck & $5(5.6)$ \\
& Unknown primary & $1(1.1)$ \\
I & $5(5.6)$ \\
& II & $17(18.9)$ \\
& III & $19(21)$ \\
& IV & $44(48.9)$ \\
& Not applicable & $5(5.6)$ \\
\hline
\end{tabular}

Statistical analysis. Statistical analysis was done using SPSS (PASW v18, SPSS Inc, Chicago, IL, USA) (13) and R Studio (R version 3.3.2 and RStudio 1.0.136, the R Foundation for Statistical Computing, Vienna, Austria) $(14,15)$ to perform descriptive patients characteristic at baseline, survival analysis using Kaplan-Meier and log rank test using cancer overall survival censored by Sars-CoV-2 (patient died of SARS-COV2 or not). Contingency tables with diagnosis, stage, comorbidities, CBC parameters, treatment type, grouped by SARS-COV2 survival status ( 0 or 1$)$ were done along with $t$-test or Fisher exact test for each group. $p$-Values less than 0.05 were considered significant.

\section{Results}

Between May and December 2020, 2,401 patients presented in our Oncology and Radiotherapy Department for treatment. Ninety patients were positive for SARS-CoV2 infection by RT-PCR testing (3.74\% of patients).

Patient demographic characteristics. Patient's demographic characteristics showed that mean age of patients diagnosed with SARS-COV2 was $59.7 \pm 12.1$ years (range $=30-83$ ), median age 62 years old. Most of them were women 52 $(57.7 \%)$. Most frequent localization of cancer was breast $(\mathrm{n}=28,31.1 \%)$ followed by colorectal $(\mathrm{n}=11,12.2 \%)$, lung cancer $(\mathrm{n}=8,8.8 \%)$, uterine cancer (squamous cell carcinoma of the cervix and uterine adenocarcinoma, $\mathrm{n}=8,8.8 \%$ ) and glioma $(\mathrm{n}=5,5.6 \%)$.

Most cancer patients diagnosed with SARS-CoV-2 infection were stage IV disease $(n=44,48.9 \%)$ followed by stage III $(n=19,21.1 \%)$ while 17 patients had stage II disease (18.9\%), 5 patients were stage I (5.5\%) and 5 patients had tumors that are not staged by TNM like central nervous system tumors. 
Table II. Patient comorbidities correlated with SARS-COV2 infection death risk.

\begin{tabular}{|c|c|c|c|c|c|}
\hline Parameter & Response & $\begin{array}{c}\text { SARS-COV2 infections } \\
\text { without death } \mathrm{N}=85(94.4 \%)\end{array}$ & $\begin{array}{l}\text { SARS-COV2 related } \\
\text { deaths } \mathrm{N}=5(5.6 \%)\end{array}$ & $\begin{array}{l}\text { Total } \\
\mathrm{N}=90\end{array}$ & $p$-Value* \\
\hline \multirow[t]{2}{*}{ Cardiac dysfunction } & No & $64(75.3)$ & $3(60)$ & $67(74.4)$ & \multirow[t]{2}{*}{0.599} \\
\hline & Yes & $21(24.7)$ & $2(40)$ & $23(25.6)$ & \\
\hline \multirow[t]{2}{*}{ High blood pressure } & No & $58(68.2)$ & $1(20)$ & $59(65.6)$ & \multirow[t]{2}{*}{0.046} \\
\hline & Yes & $27(31.8)$ & $4(80)$ & $31(34.4)$ & \\
\hline \multirow[t]{2}{*}{ Lung disease } & No & $78(91.8)$ & $4(80)$ & $82(91.1)$ & \multirow[t]{2}{*}{0.379} \\
\hline & Yes & $7(8.2)$ & $1(20)$ & $8(8.9)$ & \\
\hline \multirow[t]{2}{*}{ Dyslipidemia } & No & $82(96.5)$ & $5(100)$ & $87(96.7)$ & \multirow[t]{2}{*}{1} \\
\hline & Yes & $3(3.5)$ & 0 & $3(3.3)$ & \\
\hline \multirow[t]{2}{*}{ Obesity } & No & $70(82.4)$ & $5(100)$ & $75(83.3)$ & \multirow[t]{2}{*}{0.585} \\
\hline & Yes & $15(17.6)$ & 0 & $15(16.7)$ & \\
\hline \multirow[t]{2}{*}{ Type 2 diabetes } & No & $73(85.9)$ & $4(80)$ & $77(85.6)$ & \multirow[t]{2}{*}{0.550} \\
\hline & Yes & $12(14.1)$ & $1(20)$ & $13(14.4)$ & \\
\hline
\end{tabular}

N, Number of cases. *Fisher's exact test.

Table III. SARS-COV2 infection related complications.

\begin{tabular}{|c|c|c|c|c|c|}
\hline $\begin{array}{l}\text { SARS-COV2 } \\
\text { complication }\end{array}$ & $\begin{array}{l}\text { Toxicity } \\
\text { (Yes/No) }\end{array}$ & $\begin{array}{l}\text { SARS-COV2 infections } \\
\text { without death } \mathrm{N}=85(94.4 \%)\end{array}$ & $\begin{array}{c}\text { SARS-COV2 } \\
\text { deaths } \mathrm{N}=5(5.6 \%)\end{array}$ & $\begin{array}{l}\text { Total } \\
\mathrm{N}=90\end{array}$ & $p$-Value* \\
\hline \multirow[t]{2}{*}{ Pneumonia } & No & $68(80)$ & $2(40)$ & $70(77.8)$ & 0.071 \\
\hline & Yes & $17(20)$ & $3(60)$ & $20(22.2)$ & \\
\hline \multirow[t]{2}{*}{ Pleural effusion } & No & $78(91.8)$ & 0 & $78(86.7)$ & $<0.001$ \\
\hline & Yes & 7 (8.2) & $5(100)$ & $12(13.3)$ & \\
\hline \multirow[t]{2}{*}{ Anemia } & No & $61(71.8)$ & $1(20)$ & $62(68.9)$ & 0.031 \\
\hline & Yes & $24(28.2)$ & $4(80)$ & $28(31.1)$ & \\
\hline \multirow[t]{2}{*}{ Leucopenia } & No & 66 (77.6) & $2(40)$ & $68(75.6)$ & 0.092 \\
\hline & Yes & $19(22.4)$ & $3(60)$ & $22(24.4)$ & \\
\hline \multirow[t]{2}{*}{ Lymphopenia } & No & $47(52.2)$ & 0 & $47(52.2)$ & 0.023 \\
\hline & Yes & $38(45.2)$ & $5(100)$ & $43(47.8)$ & \\
\hline \multirow[t]{2}{*}{ Neutropenia } & No & $71(83.5)$ & $2(40)$ & $73(81.1)$ & 0.045 \\
\hline & Yes & $14(16.5)$ & $3(60)$ & 17 (18.9) & \\
\hline \multirow[t]{2}{*}{ Thrombocytopenia } & No & $75(88.2)$ & 0 & $75(83.3)$ & $<0.001$ \\
\hline & Yes & $10(11.8)$ & $5(100)$ & 15 (16.7) & \\
\hline \multirow[t]{2}{*}{ Gastrointestinal } & No & 77 (90.6) & $2(40)$ & $79(87.8)$ & 0.012 \\
\hline & Yes & $8(9.4)$ & $3(60)$ & $11(12.2)$ & \\
\hline \multirow[t]{2}{*}{ Respiratory failure } & No & $74(87.1)$ & $1(20)$ & $75(83.3)$ & $<0.001$ \\
\hline & Yes & $11(12.9)$ & $4(80)$ & $15(16.7)$ & \\
\hline
\end{tabular}

$\mathrm{N}$, Number of cases. *Fisher's exact test.

Regarding the intend of treatment when SARS-CoV-2 infection was diagnosed, 30 patients $(33.3 \%)$ were undergoing adjuvant therapy, 18 patients (20\%) were during neoadjuvant treatment with curative intent, 40 patients $(44.5 \%)$ were undergoing treatment with palliative intend and 2 patients (2.22\%) were diagnosed at first post-therapeutic follow-up visit. SARS-Cov2 infection was diagnosed during chemotherapy in $40(44.4 \%)$ patients, during radiotherapy $(\mathrm{n}=22,24.4 \%), 15$ $(16.7 \%)$ patients were undergoing concurrent chemoradiotherapy, 6 (6.7\%) patients were during immunotherapy, and $5(5.6 \%)$ patients were under hormonal therapy.
Comorbidities. Most common comorbidity in the study group was hypertension $(n=31)$ followed by cardiac dysfunction $(n=23)$ and type II diabetes $(n=13)$. Patients with hypertension had a higher risk of death due to SARS-CoV-2 infection compared to patients with normal blood pressure ( $p=0.046$ ). In contingency Table II we have summarized the main SARS-CoV-2 comorbidities grouped by SARS-CoV-2 related death and Fisher's exact test was used to compare the two groups.

In our study sample, $3.3 \%$ patients were underweight, $32.2 \%$ had normal weight, $25.6 \%$ were overweight and 


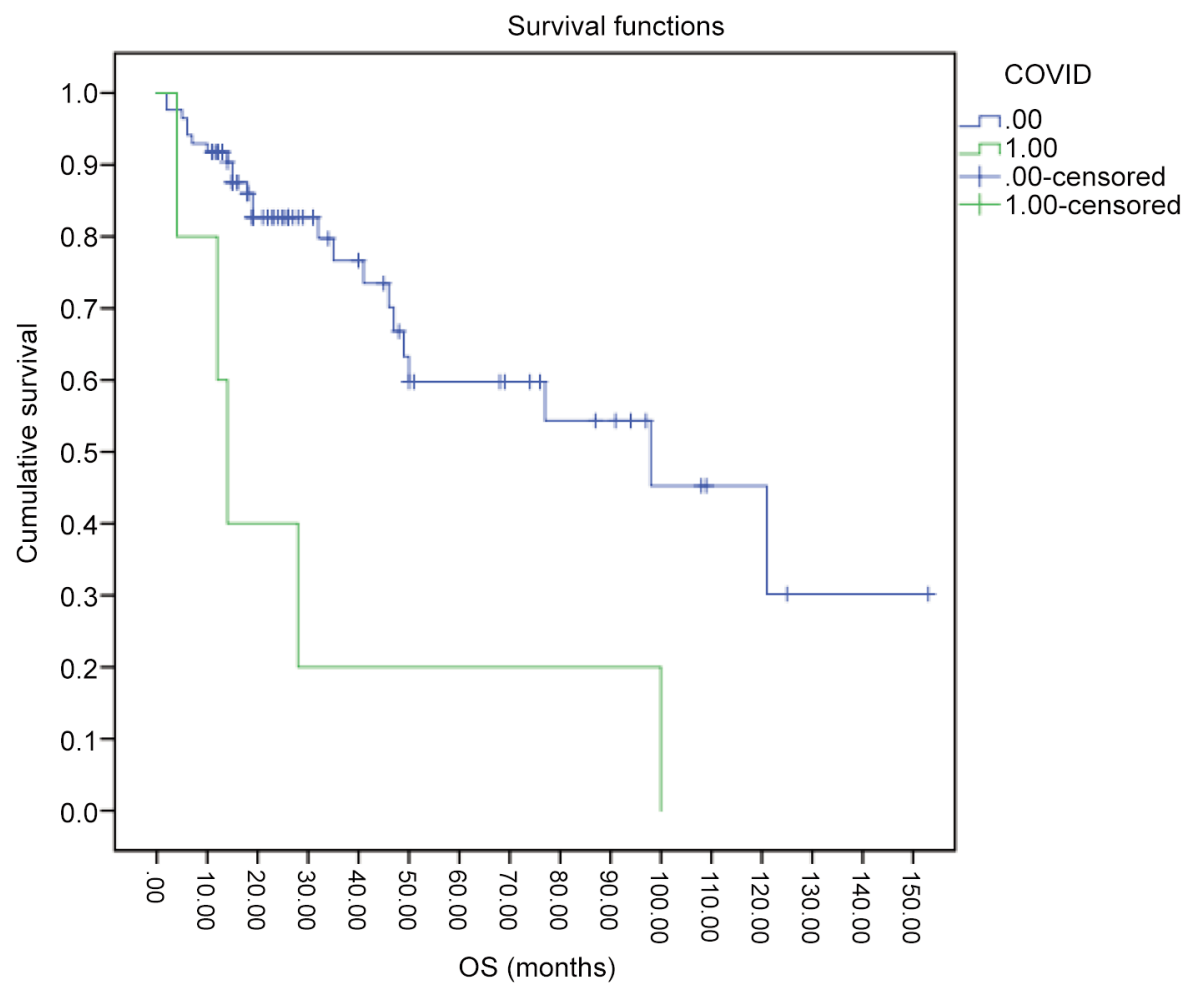

Figure 1. Kaplan Meier curves comparing cancer-related mortality and COVID mortality.

$18.9 \%$ were obese. Mean body mass index (BMI) for the entire patient population was $26.08 \mathrm{~kg} / \mathrm{m}^{2}$ (range $=18-45$ $\mathrm{kg} / \mathrm{m}^{2}$ ). No link has been identified regarding the infectious outcome of patients and BMI.

SARS-CoV-2 infection outcome and complication. Associated to the intensity of symptoms linked to SARS-COV-2 infection, $27(30 \%)$ patients needed hospitalization, 4 (4.4\%) patients had severe symptoms (needing admission in intensive care unit), 17 (18.8\%) patients had mild symptoms, $6(6.66 \%)$ patients presented minor symptoms and in 40 $(44.4 \%)$ patients the infection was diagnosed during weekly routine testing.

Common COVID symptoms were hardly found in our study population. Therefore, higher than $38^{\circ} \mathrm{C}$ fever was recorded in $7(7.7 \%)$ patients, anosmia in $4(4.4 \%)$ patients, cough in $6(6.6 \%)$ patients and headaches in $3(3.3 \%)$ patients.

The most frequent abnormalities identified during and immediately following COVID infection were hematologic (Table III): lymphopenia $(n=34,17$ patients grade 1,5 patients grade 2, 7 patients grade 3 and 5 patients grade 4) followed by anemia $(n=19,11$ patients with grade 1,8 patients with grade 2$)$, leucopenia ( $\mathrm{n}=12$ patients, 4 patients grade 1, 7 patients with grade 2, 1 patient grade 3), neutropenia $(n=7,3$ patients with grade 1,2 patients grade 2 and 2 patients grade 3 ) and thrombocytopenia ( $n=5,4$ grade 1 and 1 grade 2 ). The respiratory complications were acute pneumonia $(n=12)$, respiratory failure $(n=8)$ and pleural effusion $(n=2)$. In patients who died, 2 had grade $3 / 4$ lymphopenia, 1 had massive pleural effusion, 1 had grade 3 thrombocytopenia. An increased incidence of fatigability was identified in 19 patients $(21.11 \%)$.

Impact of SARS-CoV-2 infection on oncologic outcome. After a median cancer follow-up of 22.5 months, $5(5.55 \%)$ patients died as a result of SARS-COV2 infection out of which 2 were being treated for breast cancer, 2 for bronchopulmonary cancer and 1 for colorectal cancer. All death events caused by SARS-COV-2 infection were recorded at an advanced stage (3 in stage IV and 2 in stage III disease). Four patients were treated with palliative intention and one patient in adjuvant setting. Twenty-two cancer death, non-COVID related were recorded.

SARS-CoV-2 infection was associated with an increase in mortality rates. Median estimated overall survival was 14 months in patients who died because of COVID infection compared to 98 months in cancer related mortality analysis $(p<0.0001)$ (Figure 1). The risk of death was increased by 4 times due to SARS-COV-2 infection $(\mathrm{HR}=4.12, p=0.005$, $96 \% \mathrm{CI}=1.53-11.10)$. 


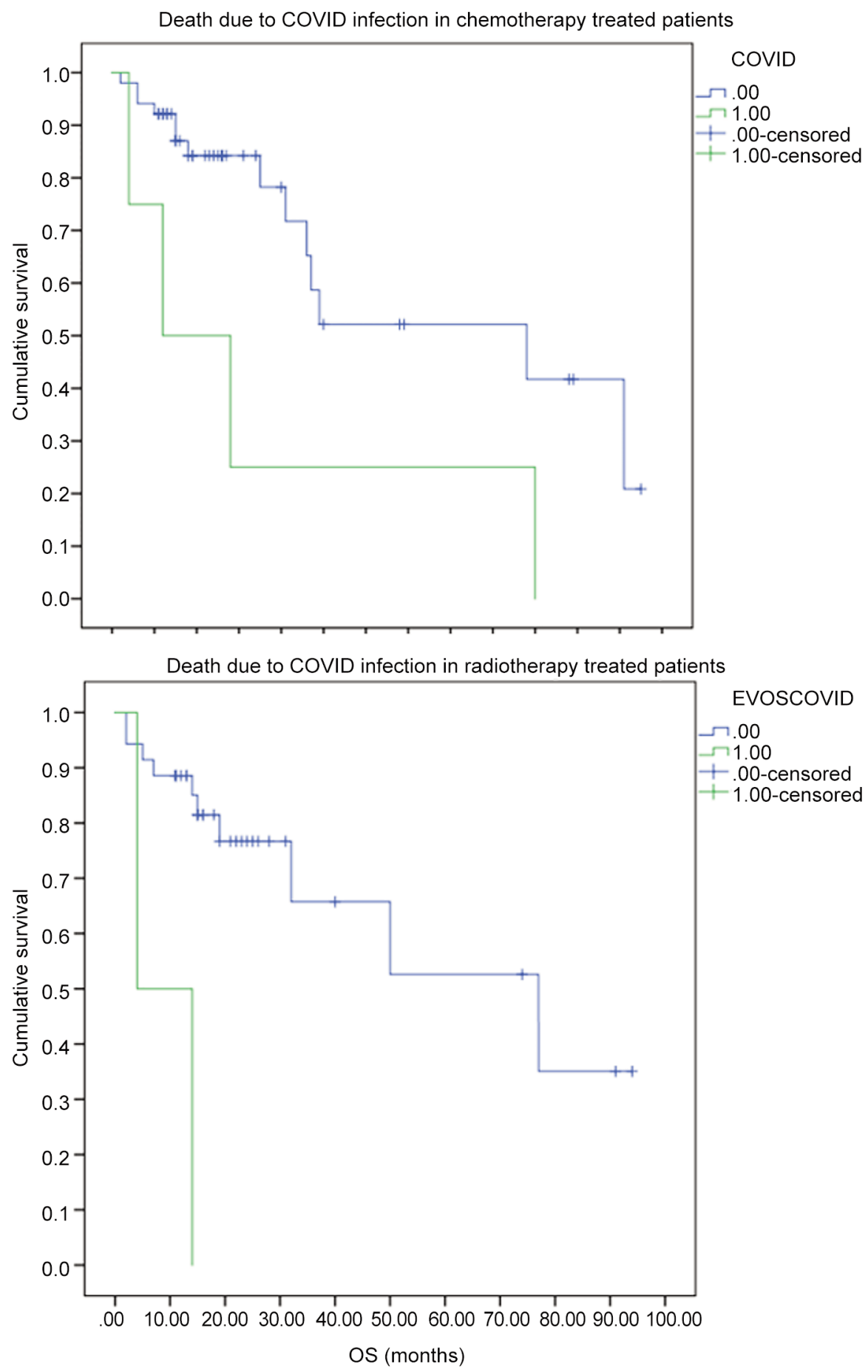

Figure 2. Kaplan Meier curves comparing cancer-related mortality and COVID mortality in patients who underwent chemotherapy, radiotherapy.

In patients receiving chemotherapy 3 deaths due to COVID occurred compared to 1 death in chemo-radiotherapy group and 1 death in radiotherapy group. No deaths were reported in patients treated with immunotherapy, targeted therapy and hormonotherapy. Statistical significance was not reached due to small numbers of events. The excess of mortality in chemotherapy and radiotherapy treatment group is shown in Figure 2. 
Overall survival was worse for patients with thrombocytopenia ( $\log$ rank $p=0.002)$, lymphopenia ( $\log$ rank $p=0.05$ ), arterial hypertension (Table II, $p=0.019$ ).

Regarding the intensity of oncological treatment, patients were postponed until a negative RT-PCR test was obtained. This translates in a median delay of oncologic treatment of 4.17 weeks (range=2-12). Additionally, three patients discontinued oncologic treatment.

\section{Discussion}

The outbreak of coronavirus disease 2019 (COVID-19) has rapidly spread globally since it was first detected and identified as a public health emergency of major international concern and has now been declared a pandemic by the World Health Organization (WHO) (16).

An early report by Zhang and colleagues (17) represents an important preliminary contribution to our understanding of the risk and effects of COVID-19 infection in cancer patients, and may allow oncologists to tailor clinical management of COVID-19 to our patients. Cancer patients are at higher risk of developing infections because they are immunocompromised due to the underlying malignancy or anticancer therapy and because of frequent visits to the hospital (18).

A retrospective cohort study included 28 cancer patients with confirmed COVID-19 from three designated hospitals in Wuhan, China. The following clinical features were shown in our cohort: fever $(82.1 \%)$, dry cough $(22,81 \%)$, and dyspnoea $(50.0 \%)$, along with lymphopenia $(82.1 \%)$, high level of highsensitivity C-reactive protein $(82.1 \%)$, anemia $(75.0 \%)$, and hypoproteinemia $(89.3 \%)$. total of $15(53.6 \%)$ patients had severe events and the mortality rate was $28.6 \%$ (17).

Another cohort study aimed to evaluate the clinical impact of COVID-19 in patients with cancer (CCC19) enrolled 928 patients. Median age was 66 years and 468 (50\%) patients were male. The most prevalent malignancies were breast [191 (21\%)] and prostate [152 (16\%)]. $366(39 \%)$ patients were on active anticancer treatment, and 396 (43\%) had active (measurable) cancer. The mortality rate in this early cohort (April-May 2020) was 13\%. Independent factors associated with increased 30-day mortality were older age, smoking status, ECOG 2 or higher and active cancer (progressing vs. remission) (19).

In our group of included patients, $3.74 \%$ were diagnosed with SARS-COV-2 infection during wave 1 and 2 of the pandemic and the mortality rate was $5.55 \%$. Until 31 December 2020 a total of 630,000 cases and 17,500 deaths due to SARS-CoV-2 were recorded in Romania representing 3.3\% of population infected and a mortality rate of $2.77 \%$ (20).

More than the immediate impact of COVID-19 infection, devastating effects on patients with cancer is with huge numbers of missed diagnoses and delayed treatments due to health systems under pressure and patient reluctance to seek medical care $(21,22)$.

Our study shows that cancer care was generally affected by the COVID-19 pandemic and delays in both chemotherapy and radiotherapy were recorded. Most aspects of care, counting diagnosis, treatment, palliative care, and follow-up were reduced during the pandemic. It is likely that these reductions will result in suboptimal treatment for at least a proportion of patients who would have been diagnosed with cancer in this period (23).

Miyashita et al. (24) showed that patients with cancer were intubated significantly more often. Dividing patients by age groups, we detected a significantly increased risk of intubation and mortality in patients with cancer aged 52-71 years.

Hematological abnormalities like neutropenia, thrombocytopenia and lymphopenia were reported by many studies at baseline of SARS-COV-2 infection $(25,26)$. In our lot of patients, lymphopenia, thrombocytopenia and neutropenia were statistically significant associated with death due to SARS-Cov-2 infection.

In a prospective observational study, Lennard et al. aimed to assess that cancer patients on cytotoxic chemotherapy or other anticancer treatment are at an increased risk of mortality from SARS CoV-2 disease compared with those not on active treatment (27). From 800 patients with a diagnosis of cancer and symptomatic COVID-19, 281 (35\%) patients had been treated with cytotoxic chemotherapy inside a month prior to testing positive for COVID-19, $44(6 \%)$ patients received immunotherapy, 64 (8\%) were on hormonal therapy, 76 (10\%) received radiotherapy and $72(9 \%)$ targeted therapies. This study discovered that there were no huge contrasts in mortality in patients receiving first-line palliative chemotherapy contrasted to those getting later lines of palliative treatment after adjustments for age, sex, and comorbidities. Patients on immunotherapy, hormonal therapy, radiotherapy, and targeted therapies were also not at any additional risk of death after adjustment for age, gender, and comorbidities compared with those who were not on these therapies.

Many studies identified the cancer population to be at a higher risk of death due to Sars-CoV-2 infection. A population-based analysis aims to evaluate the impact of solid cancer on in-hospital mortality overall and among different subgroups of patients with COVID-19 in Belgium and identify that solid cancer is an independent adverse prognostic factor for in-hospital mortality among patients with COVID-19 (31.7\% vs. $20.0 \%$, respectively; adjusted OR $(\mathrm{aOR})=1.34 ; 95 \% \mathrm{CI}=1.13-1.58)$. This adverse effect was more pronounced among younger patients $(<60$ years old, $\mathrm{OR}=3.84)$ those without other comorbidities $(\mathrm{OR}=2.27$, 95\% CI=1.41-3.64) (28).

One of the limitations of our study is the lack of more detailed information regarding COVID infection because at the beginning of pandemic the patients were transferred in 
dedicated centers and the lack of control group. Unfortunately, the pandemic is far away from ending in our country, so we expect an increase of the negative aspects revealed by this study.

As a conclusion, in our study population SARS-CoV-2 infection was associated with an increase in the mortality rates, especially in patients with advanced and metastatic disease and in patients receiving immunosuppressing treatment such as chemotherapy and radiotherapy sequential or concurrent.

\section{Conflicts of Interest}

The Authors declare that there are no conflicts of interest.

\section{Authors' Contributions}

Oana Gabriela Trifanescu: Literature research, statistical analysis, study protocol. Laurentia Gales: manuscript editing, proofreading, oncology expertise. Xenia Bacinschi: co-editing and proofreading the article. Luiza Serbanescu (corresponding author): manuscript organization, protocol design, data acquisition model. Mihai Georgescu: proofreading, editing, literature review. Alexandra Sandu: data acquisition, manuscript structure, literature review. Alexandru Michire: data wrangling, statistical analysis. Rodica Anghel: study protocol, proofreading, editing, oncology and radiation therapy expertise.

\section{References}

1 Atzrodt CL, Maknojia I, McCarthy RDP, Oldfield TM, Po J, Ta KTL, Stepp HE and Clements TP: A Guide to COVID-19: a global pandemic caused by the novel coronavirus SARS-CoV-2. FEBS J 287(17): 3633-3650, 2020. PMID: 32446285. DOI: $10.1111 /$ febs. 15375

2 Hasöksüz M, Kiliç S and Saraç F: Coronaviruses and SARSCOV-2. Turk J Med Sci 50(SI-1): 549-556, 2020. PMID: 32293832. DOI: $10.3906 / \mathrm{sag}-2004-127$

3 Liu YC, Kuo RL and Shih SR: COVID-19: The first documented coronavirus pandemic in history. Biomed J 43(4): 328-333, 2020. PMID: 32387617. DOI: 10.1016/j.bj.2020.04.007

4 Coronavirus COVID-19 (2019-nCoV). Available at: https:// www.arcgis.com/apps/dashboards/bda7594740fd40299423467b4 8e9ecf6 [Last accessed on September 26, 2021]

5 Karan A, Klompas M, Tucker R, Baker M, Vaidya V, Rhee C and CDC Prevention Epicenters Program: The risk of SARSCoV-2 transmission from patients with undiagnosed Covid-19 to roommates in a large academic medical center. Clin Infect Dis: ciab564, 2021. PMID: 34145449. DOI: 10.1093/cid/ciab564

6 Yanover C, Mizrahi B, Kalkstein N, Marcus K, Akiva P, Barer Y, Shalev V and Chodick G: What factors increase the risk of complications in SARS-CoV-2-infected patients? A cohort study in a nationwide Israeli health organization. JMIR Public Health Surveill 6(3): e20872, 2020. PMID: 32750009. DOI: $10.2196 / 20872$

7 Russell B, Moss CL, Shah V, Ko TK, Palmer K, Sylva R, George G, Monroy-Iglesias MJ, Patten P, Ceesay MM, Benjamin
R, Potter V, Pagliuca A, Papa S, Irshad S, Ross P, Spicer J, Kordasti S, Crawley D, Wylie H, Cahill F, Haire A, Zaki K, SitaLumsden A, Josephs D, Enting D, Swampillai A, Sawyer E, D'Souza A, Gomberg S, Harrison C, Fields P, Wrench D, Rigg A, Sullivan R, Kulasekararaj A, Guy's Cancer Real World Evidence, Dolly S and Van Hemelrijck M: Risk of COVID-19 death in cancer patients: an analysis from Guy's Cancer Centre and King's College Hospital in London. Br J Cancer 125(7): 939-947, 2021. PMID: 34400804. DOI: 10.1038/s41416-021$01500-\mathrm{z}$

8 Delinasios GJ, Fragkou PC, Gkirmpa AM, Tsangaris G, Hoffman RM and Anagnostopoulos AK: The experience of Greece as a model to contain COVID-19 infection spread. In Vivo 35(2): 1285-1294, 2021. PMID: 33622932. DOI: 10.21873/invivo. 12380

9 Lee LYW, Cazier JB, Starkey T, Briggs SEW, Arnold R, Bisht V, Booth S, Campton NA, Cheng VWT, Collins G, Curley HM, Earwaker P, Fittall MW, Gennatas S, Goel A, Hartley S, Hughes DJ, Kerr D, Lee AJX, Lee RJ, Lee SM, Mckenzie H, Middleton CP, Murugaesu N, Newsom-Davis T, Olsson-Brown AC, Palles C, Powles T, Protheroe EA, Purshouse K, Sharma-Oates A, Sivakumar S, Smith AJ, Topping O, Turnbull CD, Várnai C, Briggs ADM, Middleton G, Kerr R and UK Coronavirus Cancer Monitoring Project Team: COVID-19 prevalence and mortality in patients with cancer and the effect of primary tumour subtype and patient demographics: a prospective cohort study. Lancet Oncol 21(10): 1309-1316, 2020. PMID: 32853557. DOI: 10.1016/S1470-2045(20)30442-3

10 Poortmans PM, Guarneri V and Cardoso MJ: Cancer and COVID-19: what do we really know? Lancet 395(10241): 18841885, 2020. PMID: 32479827. DOI: 10.1016/S01406736(20)31240-X

11 Margulis M, Erster O, Roth S, Mandelboim M and Danielli A: A magnetic modulation biosensing-based molecular assay for rapid and highly sensitive clinical diagnosis of Coronavirus disease 2019 (COVID-19). J Mol Diagn 23(12): 1680-1690, 2021. PMID: 34600139. DOI: 10.1016/j.jmoldx.2021.08.012

12 National Cancer Institute (U.S.): Common terminology criteria for adverse events: (CTCAE), 2010.

13 IBM Corp.: IBM SPSS Statistics for Windows. Armonk, NY, USA, IBM Corp.

14 R Core Team: R: A Language and Environment for Statistical Computing. Vienna, Austria, R Foundation for Statistical Computing, 2021.

15 RStudio Team: RStudio: Integrated Development for R. RStudio, PBC, 2020.

16 Lupia T, Scabini S, Mornese Pinna S, Di Perri G, De Rosa FG and Corcione S: 2019 novel coronavirus (2019-nCoV) outbreak: A new challenge. J Glob Antimicrob Resist 21: 22-27, 2020. PMID: 32156648. DOI: 10.1016/j.jgar.2020.02.021

17 Zhang H, Han H, He T, Labbe KE, Hernandez AV, Chen H, Velcheti V, Stebbing J and Wong KK: Clinical characteristics and outcomes of COVID-19-infected cancer patients: a systematic review and meta-analysis. J Natl Cancer Inst 113(4): 371-380, 2021. PMID: 33136163. DOI: 10.1093/jnci/djaa168

18 Fong D, Rauch S, Petter C, Haspinger E, Alber M and Mitterer $\mathrm{M}$ : Infection rate and clinical management of cancer patients during the COVID-19 pandemic: experience from a tertiary care hospital in northern Italy. ESMO Open 5(3): e000810, 2020. PMID: 32527730. DOI: 10.1136/esmoopen-2020-000810 
19 Kuderer NM, Choueiri TK, Shah DP, Shyr Y, Rubinstein SM, Rivera DR, Shete S, Hsu CY, Desai A, de Lima Lopes G Jr, Grivas P, Painter CA, Peters S, Thompson MA, Bakouny Z, Batist G, Bekaii-Saab T, Bilen MA, Bouganim N, Larroya MB, Castellano D, Del Prete SA, Doroshow DB, Egan PC, Elkrief A, Farmakiotis D, Flora D, Galsky MD, Glover MJ, Griffiths EA, Gulati AP, Gupta S, Hafez N, Halfdanarson TR, Hawley JE, Hsu E, Kasi A, Khaki AR, Lemmon CA, Lewis C, Logan B, Masters T, McKay RR, Mesa RA, Morgans AK, Mulcahy MF, Panagiotou OA, Peddi P, Pennell NA, Reynolds K, Rosen LR, Rosovsky R, Salazar M, Schmidt A, Shah SA, Shaya JA, Steinharter J, Stockerl-Goldstein KE, Subbiah S, Vinh DC, Wehbe FH, Weissmann LB, Wu JT, Wulff-Burchfield E, Xie Z, Yeh A, Yu PP, Zhou AY, Zubiri L, Mishra S, Lyman GH, Rini BI, Warner JL and COVID-19 and Cancer Consortium: Clinical impact of COVID-19 on patients with cancer (CCC19): a cohort study. Lancet 395(10241): 1907-1918, 2020. PMID: 32473681. DOI: $10.1016 /$ S0140-6736(20)31187-9

20 COVID Live Update: 238,477,389 Cases and 4,865,157 Deaths from the Coronavirus - Worldometer. Available at: https://www.worldometers.info/coronavirus/ [Last accessed on December 31, 2021]

21 Blay JY, Boucher S, Le Vu B, Cropet C, Chabaud S, Perol D, Barranger E, Campone M, Conroy T, Coutant C, De Crevoisier R, Debreuve-Theresette A, Delord JP, Fumoleau P, Gentil J, Gomez F, Guerin O, Jaffré A, Lartigau E, Lemoine C, Mahe MA, Mahon FX, Mathieu-Daude H, Merrouche Y, PenaultLlorca F, Pivot X, Soria JC, Thomas G, Vera P, Vermeulin T, Viens P, Ychou M and Beaupere S: Delayed care for patients with newly diagnosed cancer due to COVID-19 and estimated impact on cancer mortality in France. ESMO Open 6(3): 100134, 2021. PMID: 33984676. DOI: 10.1016/j.esmoop. 2021.100134

22 Kumar D and Dey T: Treatment delays in oncology patients during COVID-19 pandemic: A perspective. J Glob Health 10(1): 010367, 2020. PMID: 32566158. DOI: 10.7189/jogh. 10.010367

23 Li J, Wang H, Geng C, Liu Z, Lin Y, Nie J, Sun G, Ouyang Q, Wang X, Li X, Liu Y, Chen Q, Fu P, Yao F, Chen J, Chen Y, Zhao H, Yin Y, Zhang J, Chen J, Kong X, Cheng J, Zhang H, Peng S, Wang G, Jin F, Liu Y, Wu G, Sun S and Jiang Z: Suboptimal declines and delays in early breast cancer treatment after COVID-19 quarantine restrictions in China: A national survey of 8397 patients in the first quarter of 2020. EClinicalMedicine 26: 100503, 2020. PMID: 32989430. DOI: 10.1016/j.eclinm.2020.100503

24 Miyashita H, Mikami T, Chopra N, Yamada T, Chernyavsky S, Rizk D and Cruz C: Do patients with cancer have a poorer prognosis of COVID-19? An experience in New York City. Ann Oncol 31(8): 1088-1089, 2020. PMID: 32330541. DOI: 10.1016/ j.annonc. 2020.04 .006
25 Lee RJ, Wysocki O, Bhogal T, Shotton R, Tivey A, Angelakas A, Aung T, Banfill K, Baxter M, Boyce H, Brearton G, Copson E, Dickens E, Eastlake L, Gomes F, Hague C, Harrison M, Horsley L, Huddar P, Hudson Z, Khan S, Khan UT, Maynard A, McKenzie H, Palmer D, Robinson T, Rowe M, Thomas A, Tweedy J, Sheehan R, Stockdale A, Weaver J, Williams S, Wilson C, Zhou C, Dive C, Cooksley T, Palmieri C, Freitas A and Armstrong AC: Longitudinal characterisation of haematological and biochemical parameters in cancer patients prior to and during COVID-19 reveals features associated with outcome. ESMO Open 6(1): 100005, 2021. PMID: 33399072. DOI: $10.1016 /$ j.esmoop.2020.100005

26 Tavakolpour S, Rakhshandehroo T, Wei EX and Rashidian M: Lymphopenia during the COVID-19 infection: What it shows and what can be learned. Immunol Lett 225: 31-32, 2020. PMID: 32569607. DOI: 10.1016/j.imlet.2020.06.013

27 Lee LY, Cazier JB, Angelis V, Arnold R, Bisht V, Campton NA, Chackathayil J, Cheng VW, Curley HM, Fittall MW, FreemanMills L, Gennatas S, Goel A, Hartley S, Hughes DJ, Kerr D, Lee AJ, Lee RJ, McGrath SE, Middleton CP, Murugaesu N, Newsom-Davis T, Okines AF, Olsson-Brown AC, Palles C, Pan Y, Pettengell R, Powles T, Protheroe EA, Purshouse K, SharmaOates A, Sivakumar S, Smith AJ, Starkey T, Turnbull CD, Várnai C, Yousaf N, UK Coronavirus Monitoring Project Team., Kerr R and Middleton G: COVID-19 mortality in patients with cancer on chemotherapy or other anticancer treatments: a prospective cohort study. Lancet 395(10241): 1919-1926, 2020. PMID: 32473682. DOI: 10.1016/S0140-6736(20)31173-9

28 de Azambuja E, Brandão M, Wildiers H, Laenen A, Aspeslagh S, Fontaine C, Collignon J, Lybaert W, Verheezen J, Rutten A, Vuylsteke P, Goeminne JC, Demey W, Van Beckhoven D, Deblonde J, Rottey S, Geukens T, Punie K, Belgian Collaborative Group on COVID-19 Hospital Surveillance and the Belgian Society of Medical Oncology (BSMO)., Bafort K, Belkhir L, Bossuyt N, Colombie V, Daubresse C, Dauby N, De Munter P, Delmarcelle D, Delvallee M, Demeester R, Delefortrie Q, Dugernier T, Holemans X, Louviaux I, Machurot P, Minette P, Mokrane S, Nachtergal C, Noirhomme S, Piérard D, Rossi C, Schirvel C, Sermijn E, Staelens F, Triest F, Van Beckhoven D, Van Goethem N, Van Praet J, Vanhoenacker A, Verstraete R, Willems E and Wyndham-Thomas C: Impact of solid cancer on in-hospital mortality overall and among different subgroups of patients with COVID-19: a nationwide, population-based analysis. ESMO Open 5(5): e000947, 2020. PMID: 32978251. DOI: 10.1136/esmoopen-2020-000947

Received November 10, 2021

Revised December 1, 2021

Accepted December 17, 2021 